\title{
LA NADA COMO CATEGORÍA ONTOLÓGICA EN EL VIDEOJUEGO: ANÁLISIS DE SAD SATAN
}

\section{The Nothingness as an Ontological Category on the Video Fame: Analyzing Sad Satan}

\author{
Dr. Aarón RODRÍGUEZ SERRANO \\ Universitat Jaume I: Personal Investigador Contratado Doctor, España. \\ E-mail: serranoa@uji.es \\ (D) http:/ / orcid.org/0000-0002-3858-1045
}

Fecha de recepción del artículo: 01/02/2017

Fecha de aceptación definitiva: 16/03/2017

\begin{abstract}
RESUMEN
El presente trabajo pretende explorar las posibilidades de la nada como categoría ontológica en la construcción de mundos virtuales. Se trata de una investigación que se encuadra dentro del estudio metafísico de los videojuegos, trascendiendo así las lecturas exclusivamente narratológicas para preguntarse por la manera en la que la construcción de mundos virtuales es, a su vez, deudora y divergente de nuestra propia experiencia de lo real. Para ello, en primer lugar, se propone un breve recorrido por posibles aplicaciones generales de la ontología heideggereana al mundo de los videojuegos, concretamente a partir de parámetros dispares como el tiempo, el espacio y la figura misma del videojugador. Posteriormente, se explorarán las consecuencias de este marco en un ejemplo concreto, el videojuego Sad Satan, surgido de la Deep Web de fecha y desarrollador desconocidos. Dicho análisis partirá de las herramientas metodológicas de construcción de universos virtuales -Personaje, Item y Objeto- que Siabra Fraile extractó de su lectura wittgensteniana del videojuego.
\end{abstract}

Palabras clave: Game Studies; Ontología; Videojuego; Interacción; Mecánicas ludoficcionales.

\begin{abstract}
This study tries to explore the idea of nothingness as an ontological category on the construction of virtual worlds. The research is framed in the metaphysical study of video games, trying to go over the narratological readings, and asking about the way in which the designing of virtual worlds is, at the same time, indebted to and divergent from our concrete experience of the real world. To achieve our goal, in the first place, we will try to make a brief comment about different applications of the Heideggerian ontology to the video game world, specifically using parameters such as time, space and interface. After that, we will explore the consequences of this context in the concrete analysis of Sad Satan, a video game that emerged from the Deep $W e b$ in an unknown date and was developed by an unknown company. This analysis will use the methodological tools in the building of virtual worlds -Character, Item and Object- developed by Siabra Fraile in his Wittgensteinian interpretation of the video game.
\end{abstract}

Key words: Game Studies; Ontology; Video Game; Interaction; Ludofictional mechanics. 


\section{INTRODUCCIÓN}

En 1935, en su célebre seminario de introducción a la metafísica impartido en plena vorágine del III Reich, Martin Heidegger planteó con brutalidad una pregunta clave que habría que guiar parte de su reflexión de ese año: «¿Por qué es el ente y no más bien la nada?» (2001, p. 11). La pregunta, como es bien sabido, parte del estremecimiento anterior propuesto por Leibniz en, entre otros lugares, su Sobre la originación radical de las cosas: «¿Por qué existe un mundo más bien que nada?» (Leibniz, 2011, p. 147). Y, aunque de momento no podamos centrarnos en las características concretas que se atraviesan en el uso mismo de la palabra ente en la superación heideggereana -que darían, va de suyo, para una investigación mucho más amplia-, quizá sí que podamos otorgar algo de luz al uso concreto de la palabra mundo.

Y es que, después de todo, ese es el problema principal de la hipotética ontología del videojuego que queremos esbozar aquí: las creaciones de mundos ficcionales lúdicos parecen remitir al nuestro. Cuentan con mecánicas de extrema complejidad y riqueza (Planells, 2015), que generalmente se basan en torno a parámetros de «simulación de lo real» (Frasca, 2003) que nos permiten orientarnos en ellos. En el límite, algunos autores como Ralph Koster (2005), sugieren que la posibilidad misma de la abstracción en la creación de mundos virtuales es impensable: por muy difusos que parezcan los entes que componen un videojuego, siempre remiten de alguna manera a la experiencia del usuario en su vida cotidiana. Más adelante veremos los límites que plantea esta idea.

En lugar de seguir este tipo de argumentos basados en ejercicios de reconocimiento cognitivo -pongamos por caso, un árbol virtual que remita al árbol que crece frente a la ventana de nuestra habitación-, nos gustaría esbozar que hay una conexión mucho más compleja, de naturaleza eminentemente filosófica entre todos los mundos lúdicos y nuestro mundo: lo que, de manera tentativa, podríamos llamar la total ausencia de sentido.

Y nos gustaría clarificar: esta idea en nada se opone a los sistemas metodológicos que leen los videojuegos desde ideas como reglas o recompensas (Frasca, 2009) o desde los parámetros que permiten o limitan la libertad de cada mundo (Navarro Remesal, 2016) por no hablar de aquellos que - precisamente por encontrar una fundamentación del videojuego en lo humano- proponen una cierta ética del juego (Rodríguez Serrano, 2014; Zagal, 2009). Desde la perspectiva de los autores citados, podríamos señalar que hay una conexión entre sentido y narrativa. Pongamos por caso: escapar de una invasión demoníaca en marte (Doom, iD Software, 2016), rescatar a la princesa en las diferentes entregas de la saga Super Mario, o impedir que los nazis sigan dominando el mundo en Wolfenstein: The New Order (MachineGames, 2014). Un jugador en, pongamos por caso, Call of Duty: Advanced Warfare (Sledgehammer Games/High Moon Studios, 2014), tiene la certeza de que sus actos de interactuación con el entorno van dirigidas a un triunfo racional que se concreta en la eliminación de ATLAS, el pérfido grupo paramilitar que controla el tablero geopolítico internacional. Incluso en aquellos videojuegos con narrativas claramente abiertas parece adivinarse un sentido: simplemente varían las diferentes maneras en las que el videojuegador puede atreverse a alcanzarlo. El sentido se encerraría, por tanto, en una cierta «vivencia narrativa» (Ruiz Collantes, 2013).

Ahora bien, una visión en profundidad, mucho más detenida, nos permitirá aprehender que el mundo lúdico -como ocurre, por lo demás, con el nuestro-, no tiene un sentido en sí mismo. Lo tiene, en principio, el tiempo que el videojugador invierte en resolver un puzle o conseguir alcanzar la meta: a cambio, recibe una serie de gratificaciones emocionales, narrativas, estéticas o puramente intelectuales -la adquisición o el desarrollo de ciertas destrezas. Pero el mundo del videojuego, en sí mismo, en última instancia, no tiene escrita su significación. Por mucho que queramos hacer una conversión entre el equipo de programadores y diseñadores y el famoso Dios-relojero del ya citado Leibniz, lo cierto es 
que, si contemplamos detenidamente un mapa, una mísera captura de pantalla, veremos cómo la pregunta de Heidegger retumba con toda brutalidad: «¿Por qué está eso ahí, en lugar de no haber nada?».

Pregunta brutal que nos asola, del mismo modo, cuando observamos, por ejemplo, las siguientes imágenes:

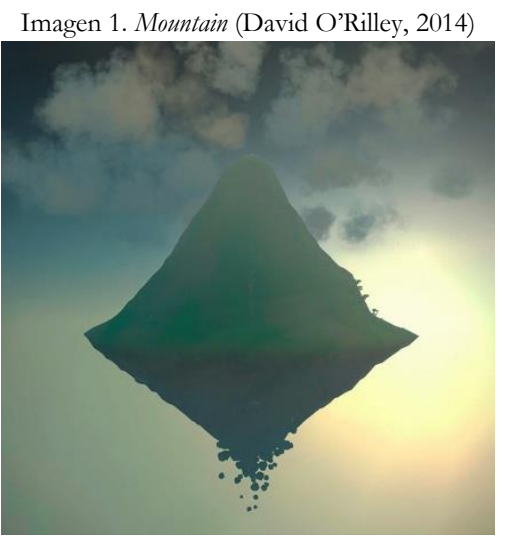

Fuente: Videojuego Mountain.

Imagen 2. Proteus (Ed Key \& David Kanaga, 2013)

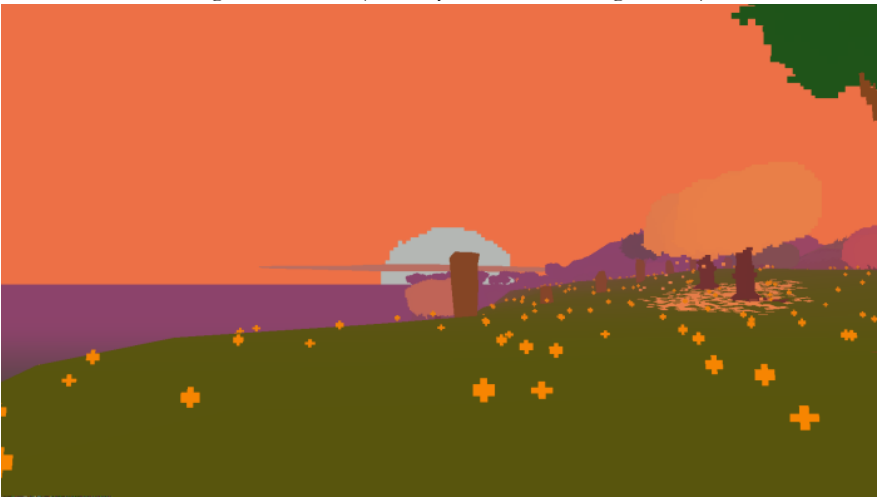

Fuente: Videojuego Proteus.

Mountain y Proteus son, en cierto sentido, dos videojuegos límite. Lo primero que muestran, antes que cualquier otra cosa, es que el ente es, en lugar de la nada. Despojan al videojuego de sus aparatajes narrativos tradicionales para reducirles a un puro sistema de mostración de lo que es. En el caso de Mountain, el videojugador está restringido a unos simples parámetros básicos: puede deslizar su mirada en torno al objeto que está representado en el universo, generar música con su teclado o recibir una serie de mensajes crípticos que se imprimen sobre la pantalla. Pero el corazón de la experiencia lúdica no es otra que la contemplación misma de lo que hay, de tomarse el tiempo (Loriguillo-López \& Sorolla-Romero, 2015) para mirar el espacio. Por acotar nuestro territorio terminológico, podríamos decir que la mecánica principal no es otra que la mirada. Experimentar las cincuenta horas en las que está marcado el ciclo de la montaña, su lluvia, sus nubes, su relación con la luz que se anuda en esa gravitación imposible que la sitúa en medio de una suerte de cosmos.

La formulación metafísica de Mountain, por supuesto, es mucho más dramática: ¿Por qué está esa montaña abi, en mitad del cosmos? ¿Y el cosmos mismo que la arropa, por qué comparece ante noso- 
tros en lugar de la nada? Ciertamente, desde una lógica que remita a nuestro uso del lenguaje según el aparataje aristotélico (2011), resulta prácticamente imposible colgar «atributos»-al menos en el contexto de la narratología de videojuegos- a esa montaña más allá de su propia apariencia física. Por supuesto, sabemos que es verde, o que flota, o incluso que es tridimensional. Sin embargo, a la hora de explicarla -esto es, de encontrar sus causas, por no hablar ya de su causa primera-, el discurso se bloquea dramáticamente: ¿para qué sirve? ¿En qué deviene? ¿Quién la ha creado?

Tanto Mountain como Proteus bloquean dramáticamente la posibilidad misma del sentido: no hay una disposición lineal (esto es, temporal) de acciones que otorguen un placer tras su consecución. Antes bien, lo que queda es simplemente la pura materialidad del videojuego, concretada en un notable vértigo ontológico: hay tierra, hay espacio, hay tiempo, hay movimiento y mirada. Lo que el jugador decida hacer con ello es su problema y, precisamente al carecer de dinámicas legibles, no se someterá con facilidad a una lectura ética (Zagal, 2009). Del mismo modo, ambos videojuegos acaban por llevar a sus últimas consecuencias lo que ya estaba esbozado en algunas de las primeras películas interactivas multimedia como The 7th Guest (Trilobyte, 1993) o Myst (Cyan Worlds, 1993). En aquellas propuestas, era la propia interactuación con el espacio -gracias al desbloqueo de puzles, zonas ocultas o a la contemplación de animaciones-, la que permitía entender cuál era el sentido de las cosas (Rodríguez Serrano, 2006) mediante una suerte de explicación simbólica que acababa incluso jugando con la imposible convergencia entre videojugador y personaje controlado. Muy al contrario, tanto Mountain como Proteus ponen encima de la mesa que la propia naturaleza del videojuego ha alcanzado una suerte de madurez histórica capaz de asumir, con toda su complejidad, la belleza y el misterio que rodea «a las cosas mismas» simplemente por ser-abí.

Nuestro trabajo pretende partir de esta brutal destilación de la experiencia misma, estrictamente fenomenológica del videojuego (Bogost, 2008), para intentar comprender cómo funcionan esos mecanismos de mostración de lo que hay en convivencia con la interactividad misma que se supone en cualquier experiencia lúdica. Para ello, hemos decidido utilizar como estudio de caso uno de los ejemplos más estimulantes de esta corriente de propuestas interactivas, por lo que tiene de experiencia diferenciada y de producto absolutamente alejado de los canales habituales de promoción, distribución y difusión convencionales: Sad Satan (Desarrollador desconocido, Año Desconocido).

\section{2. $S A D S A T A N:$ EL ENTE Y LA NADA}

Sad Satan es un videojuego desarrollado, al menos en su primera versión, casi con toda probabilidad, por los responsables del canal de YouTube Obscure Horror Corner ${ }^{1}$. El día 25 de junio de 2015 comenzó a circular el primero de los cinco gameplays considerados «oficiales» que ofrecían imágenes de su universo. Lo primero que llamaba la atención al contemplar aquel hipotético videojuego era, en puridad, su relación con la nada. De hecho, los elementos compositivos -tanto visuales como a nivel de interfaz- parecían haberse reducido al mínimo, sin que realmente se pudiera hablar de una lógica minimalista. Antes bien, la acción parecía reducirse a recorrer una suerte de pasillo gigantesco escuchando el sonido de los propios pasos, efectos de sonido distorsionados, fragmentos de canciones modificadas y contemplando breves flashes de imágenes que asaltaban al videojugador.

Probablemente, su producción no hubiera trascendido de no ser por que alrededor del video en cuestión no tardó en levantarse una suerte de creepypasta -leyenda urbana que se viraliza a través de las redes sociales- que situaba a Sad Satan como una especie de «videojuego maldito», capaz incluso de tomar el control de tu ordenador para depositar en el escritorio extraños mensajes amenazantes. En

\footnotetext{
${ }^{1}$ https://www.youtube.com/channel/UCAGyz9XuDNt9c4dJ4pchCpQ/videos [Consultado en mayo de 2016].
} 
diferentes comunidades, pero muy especialmente en Reddit, surgieron incluso canales propios $^{2}$ dedicados al paciente desciframiento de los diferentes símbolos que se iban disponiendo en los distintos gameplays y las diferentes versiones del juego que iban emergiendo, mes tras mes.

Lo que comenzó como una maniobra de marketing para conseguir visitas al canal acabó derivando en, en primer lugar, una comunidad de usuarios global que se generó una ingente bibliografía hermenéutica alrededor de la propuesta, incluyendo videoanálisis en YouTube y diferentes versiones más o menos modificadas del código original. En segundo lugar, una exquisita narración mitológica a propósito del juego: había emergido de la $D e e p W e b$, estaba vinculado de alguna manera con redes dedicadas a la distribución de material ilegal, contenía intrincados secretos a medio camino entre la literatura cyberpunk y el terror gótico convencional.

Ahora bien, lo que interesa a nuestro estudio tiene que ver, concretamente, con la experiencia misma de jugar Sad Satan. O más concretamente, con la manera en la que el propio juego bloquea con todos sus medios esa experiencia para ofrecer, en su lugar, una inquietante reflexión sobre la nada. El juego, por tanto, arranca de una paradoja: su experiencia es, ante todo, una experiencia del vacío. No poder habitar, no poder tener un espacio en el que clavar -aunque sea mínimamente- una explicación sobre lo que ocurre, sus causas, su sentido.

Hay una diferencia radical entre las sensaciones que busca despertar Sad Satan y las que se pueden localizar en otros juegos de terror más o menos convencionales como, pongamos por caso, The Evil Within (Tango Gameworks, 2014). En las grandes sagas del terror lúdico, el videojugador no siente angustia, sino miedo, en tanto puede localizar el origen de la amenaza que pone en peligro su supervivencia. Da igual que se trate de zombis, fantasmas, apariciones varias. Los enemigos están encarnados, son personajes o se inscriben de alguna manera en el relato. Muy al contrario, en Sad Satan la angustia emerge porque no hay un objeto alguno al que atribuir la naturaleza del mal: es el mundo mismo el que, de alguna manera, nos rechaza y pone en jaque nuestro estar-ahí. El mal que se escribe sobre el universo es a la vez inevitable, melancólico, descontextualizado, incontrolable. Desde el propio título se trenzan dos operadores textuales que caminan de la mano: la existencia del mal, la tristeza que provoca.

En la ficción tradicional, como es sabido, el mal tiende a narrativizarse. Casi todas las películas de fantasmas acaban explicando, más tarde o más temprano, por qué la casa, la fábrica, el cementerio, el pueblo o el faro en cuestión se encuentra efectivamente encantado (Davies, 2007). En propuestas contemporáneas que adaptan las nuevas tecnologías a los viejos códigos de la representación fantasmal, no se modifica ni un ápice esta norma básica: en The Ring (Ringu, Hideo Nakata, 1998), por mucho que Sadako se valga de cintas de video para transmitir su particular maldición, finalmente acabamos accediendo a un cierto saber sobre el origen, las causas concretas de su dolor. Volvemos a Leibniz: es más fácil que exista algo -incluso en el límite, algo tan improbable como un fantasma- precisamente porque somos capaces de localizar una causa. A su vez, más allá del texto y ya en el territorio de la pura hermenéutica, esa misma causa se puede leer desde el análisis textual, para hacer una reflexión psicoanalítica, semiótica, feminista, en clave de los estudios culturales, formalista... El relato permite encontrar un culpable del mal -la madrastra cruel, el marido asesino, la hermana celosa- que, posteriormente, puede ser transformado por el analista en una serie de hipótesis a propósito de las tensiones sociales, del mensaje reprimido, o de aquello que se pacte con los límites interpretativos de cada propuesta. En el límite, en las odas gore y los slaughters, la sociedad es la culpable, enferma en su totalidad, generadora de Leatherfaces y otros seres más o menos desquiciados (Wood, 2003). El mal es la

\footnotetext{
2 https://www.reddit.com/r/sadsatan [Consultado en mayo de 2016].
} 
familia castradora, o la religión, o los experimentos militares. Lo relevante es siempre que el mal queda ceñido en torno a unos parámetros controlables, explicables, e incluso, comunicables.

Ahora bien, es necesario romper las normas causales del horror para que de pronto nos demos cuenta de la fragilidad del mundo, o en su límite, de su ausencia de sentido -de la angustia heideggereana. Pensemos en dos antecedentes tan fascinantes, sin salir de la ficción cinematográfica, como Los pájaros (Alfred Hitchcock, The Birds, 1963) o su heredera directa y, si cabe, más cruel ¿Quién puede matar a un niño? (Narciso Ibáñez Serrador, 1976). En ambas películas el mal no puede justificarse en términos causales. Las olas de pájaros o de niños que descienden salvajemente sobre los otros para aniquilarles, simple y llanamente, ocurren. La lógica causal del relato se mantendrá inevitablemente silenciosa, y eso inevitablemente hará que nuestra experiencia del horror llegue a tener una nueva dimensión.

Ciertamente, se podría objetar que hay algo en los primeros videojuegos que bebía de esta misma lógica. Por poner un simple ejemplo, la invasión alienígena de Space Invaders (Taito Corporation, 1978) apenas tenía un desarrollo narratológico previo. El propio diseño gráfico del juego apuntaba como respuesta a la herencia de la Serie B, de un cierto aprendizaje de los códigos de la ciencia ficción, para que posteriormente el videojugador rellenara por su cuenta los «huecos de sentido» del relato. Ahora bien, en el caso de Sad Satan resulta imposible encontrar -ya sea en su ambientación o en su diseño-, elementos que lo conecten con facilidad con otros antecedentes narrativos, con otros relatos. Antes bien, estaríamos en un territorio mucho más cercano al del arte de vanguardia, al videoarte radical, al accionismo vienés, a los experimentos sonoros de Alvien Lucier, o como mucho, a las propuestas literarias de Mark Z. Danielewski.

Su propuesta, por el contrario, nos sirve para toparnos inevitablemente con uno de los llamados «límites de la ficción» (Aumont, 2016), precisamente por su incomunicabilidad. Y no nos referimos a una suerte de lógica ética sobre la inefabilidad de los discursos, como la que generalmente se ha intentado aplicar a la mostración de acontecimientos de mal puro como Auschwitz (Didi-Huberman, 2004; Lanzmann, 2011; Rodríguez Serrano, 2015). Muy al contrario: su reflexión sobre el mal es tan extrema formalmente que implica la negación misma de cualquier narrativa que lo ciña. Los miles de usuarios que en Reddit o en YouTube han intentado generar explicaciones, teorías, descifrar signos o buscar referentes, simple y llanamente, han intentado calmar sin éxito la angustia que emerge de su no saber qué ocurre en el mundo - esto es, de no saber cuál es la causa del mal, y a su vez, qué relación tiene esa causa con las mecánicas del mundo en el que se desarrolla el videojuego.

Porque -y esta es la clave- Sad Satan convierte el espacio de lo jugable en una suerte de territorio vacío en el que los procesos de significación quedan, de alguna manera, revertidos. Resulta paradójico que los mecanismos de explicación «comunitaria» que se desarrollaron en la web partieran, como nos parece indudable, de una sensación de angustia siempre subjetiva e incomunicable. Después de todo, lo que semejante vacío nos permite experimentar es la conexión entre la nada y el mal. La idea del mal como nada arranca, propiamente, en Plotino y volverá a aparecer una y otra vez tanto en la tradición cristiana de la mano de San Agustín -en el libro XII de La ciudad de Dios (De Hipona, 2006: 96-98 y 331-344)- como en el racionalismo posterior a través de ciertos párrafos de Leibniz ${ }^{3}$. El mal

\footnotetext{
${ }^{3}$ Si bien, por supuesto, para Leibniz, como queda claro en su Discurso de metafísica, el mal está bien directamente vinculado con la voluntad de Dios, o bien, a su permisividad: «Pero supongamos que [una acción] es mala en sí misma y sólo resulta buena por accidente porque el curso de las cosas y en particular el castigo y la reparación corrige su maldad y con ello se encuentra más perfección en todo lo que sigue, como si el mal no se hubiera presentado. En este caso, es preciso decir que Dios permite el mal y no que lo quiere, aunque concurra a ello debido a las leyes de la naturaleza que él ha establecido y porque sabe obtener de esto un bien mucho mayon» (Leibniz, 2011a, p. 86).
} 
se plantea, por tanto, desde una suerte de metafísica negativa: el problema no es lo que tenemos, sino propiamente, lo que nos falta.

A riesgo de torcer demasiado esta idea, en el mundo de los videojuegos se puede distinguir, al hilo de lo que venimos proponiendo, dos características diferentes de mal. La primera de ella pende directamente de manos del mímesis y es esa suerte de idea constantemente aprovechada por los medios de comunicación amarillistas que conectaría con la idea misma de la conducta maligna con la representación del mal. En este discurso, los videojuegos hablan del mal porque representan actos violentos, consiguiendo además que -cosa del todo intolerable, por supuesto- el videojugador goce de ellos. Esta idea también se puede localizar en ciertos sectores académicos, por lo habitual anglosajones, que no han dudado en celebrarla de manera un tanto obtusa, generalmente valiéndose de dudosos experimentos inspirados en la psicología cognitiva (Barlett, Harris, \& Baldassaro, 2007; Carnagey \& Anderson, 2004; Dill \& Dill, 1999) para acabar llegando a conclusiones de Pero Grullo como, por ejemplo, que la exposición sistemática a la acción de ciertos First Person Shooters genera rasgos corporales basados en la excitación y el aumento del ritmo cardíaco.

Sin embargo, como ya se ha trabajado en otros contextos (Rodríguez Serrano, 2013), no hay más que alzar la vista para darse cuenta de que todas las profecías apocalípticas tejidas en torno al consumo de elementos violentos por parte de las nuevas generaciones más o menos afterpop (Fernández Porta, 2008, 2010, 2012) no solo no se han cumplido, sino que, además, han terminado por generar conexiones ideológicas más que dudosas -véase, por ejemplo, las diatribas contra el mundo de los videojuegos protagonizadas por el inefable telepredicador Josué Yrion y las hilarantes apropiaciones por parte de la comunidad hispanoparlante. Parece indudable que las legiones de sujetos que han crecido en las últimas generaciones jugando a Wolfenstein 3D (iD Software, 1992), Mortal Kombat (Midway, 1992), el Doom original (iD Software, 1993), Carmageddon (Interplay y SCi, 1997) o Grand Theft auto (DMA Design, 1997) - por poner apenas algunos pocos ejemplos de videojuegos que funcionaron como sinónimos de fin del mundo y destrucción de los sacrosantos valores occidentales- no han tomado las calles para asesinar brutalmente a sus contemporáneos.

Luego, en oposición, pensamos que el mal que realmente merece la pena ser explorado en relación con los videojuegos no es tanto ese mal que se apoya en la mímesis, sino antes bien, siguiendo la división establecida por Siabra Fraile (2012) -autor al que volveremos en unos momentos-, el mal que se apoya en el propio modelo del videojuego. Es decir, en la manera en la que el entorno, el espacio, se revela/rebela como imposible de descifrar o de habitar. La manera, por así decirlo, en la que el espacio acaba mostrando su naturaleza de nada.

Desarrollemos esta idea. Como ya se ha demostrado desde ciertos estudios narratológicos, el uso de la violencia mimética queda, de alguna manera, controlado cuando es depositado en los marcos estructurales del relato clásico (González Requena, 2006). Ciertamente, la manera en la que videojuegos directamente relacionados con la mostración violenta, como el ya citado Mortal Kombat, han ido deviniendo relatos de gran complejidad en sus últimas entregas parece sustentar esta hipótesis. Ahora bien, lo que Sad Satan propone es, muy precisamente, poner en duda todo ese aparataje estructural para hacer que el mal se manifieste en su naturaleza más brutal, descarnada, de tal manera que no se pueda levantar sobre su experiencia ningún tipo de justificación. La dirección artística es un buen ejemplo: la nada se concretiza de manera brutal en una serie de escenarios glaciales. Los aullidos, las músicas distorsionadas, simplemente son, pero no cuentan con una fundamentación, un sentido. Están situadas en la finísima barrera metafísica del no-ser. Están ahí, sin duda, perfectamente aprehensibles por el video jugador, pero no responden a nada que no sea nuestra propia angustia. El universo lúdico 
en su totalidad, por lo tanto, deviene casi-nada, defecto, aquello que no puedo pensar en el marco de Dios -si pensamos desde San Agustín- o en el marco de la razón -si pensamos desde Leibniz ${ }^{4}$.

Pero pensemos esta misma idea del mal desde la propia teoría del análisis metafísico de los videojuegos. Volviendo a la obra de Siabra Fraile, el núcleo de sentido de un videojuego puede ser leído a través de las herramientas de Wittgenstein para generar un enlace entre objetos que genera lo que el autor ha llamado un «espacio lógico» - a lo que nosotros añadimos, esperamos que, sin torcer demasiado su escritura, un espacio «dotado de sentido»:

Si entendemos el espacio lógico como el conjunto de las posibles interdependencias de los objetos del videojuego, que aparecen en él como limitadores (y por tanto determinantes de las posibilidades) de la acción, entonces el espacio lógico es la forma de todo aquello que puede pasar dentro del videojuego. El videojuego sería el evento resultante de la relación interna entre los objetos (Siabra Fraile, 2012, p. 118).

Posteriormente, utilizando como ejemplo el videojuego The Legend of Zelda (Nintendo, 1986), el autor refinará esta idea en su aplicación a tres categorías de tipos que componen el mundo virtual: los objetos (que bloquean o permiten el paso), los personajes (que se desplazan por el espacio entrañando amenazas u oportunidades de mejora) y los items (aquellos operadores susceptibles de ser utilizados). Intentaremos, por tanto, seguir su estructura.

En primer lugar, ciertamente podemos localizar con cierta precisión la presencia de objetos en Sad Satan, si por tal entendemos los muros que generan los laberintos en los que parecemos movernos. Es curioso que el juego comience, literalmente, con una puerta que se abre. Ahora bien, después de ella, lo único que podemos hacer es transitar entre paredes estrechas y dinteles un espacio difícilmente topografiable.

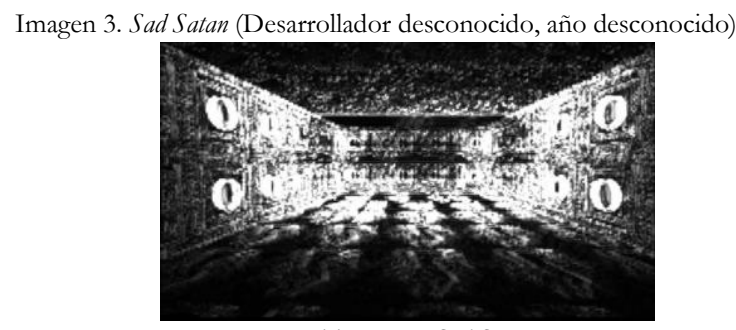

Fuente: Videojuego Sad Satan.

Esos muros generan, en efecto, un espacio sobre el que podemos proponer un movimiento - generando, por lo tanto, una cierta dinámica mínima de interacción: caminarSin embargo, resulta imposible entender nada del mundo general en el que se engloba, por no hablar de sus leyes estrictamente atmosféricas-ontológicas: ¿se trata del infierno? ¿de otra dimensión? ¿de una suerte de traducción abstracta del interior de cada jugador? Ciertamente, hay elementos reconocibles en nuestra manera de percibir el mundo desde una perspectiva exclusivamente cognitiva -digamos: hay puntos de fuga, hay una perspectiva que sitúa nuestra mirada en una hipotética primera persona, hay texturas que

\footnotetext{
${ }^{4}$ Si el lector es tan amable de retornar a la cita reproducida en la anterior nota a pie de página podrá comprobar que, en efecto, Leibniz acaba conectando la permisividad/voluntad de Dios con las propias leyes de la naturaleza que él ha establecido. Esas leyes de la naturaleza, aunque sea en una gradación menor que la de Spinoza, pueden ser de alguna manera aprehendidas con el correcto uso de la razón.
} 
cubren los muros laterales, algo que podría ser un cielo interminable, recodos... Sin embargo, no hay ninguna lógica interior, inherente al espacio. El espacio simplemente es, pero paradójicamente, cualquier anclaje que intentemos situar sobre su ser apunta directamente a la nada. No es, dicho con absoluta claridad, un espacio simbolizable.

Sad Satan bloquea cualquier tipo de lectura del movimiento y el espacio en el juego ya que la división interior/exterior o los conceptos vida/muerte no pueden ser aplicados a las características del espacio. Por un lado, en efecto, se nos recuerda una y otra vez la presencia de la muerte, no solo a partir de las imágenes violentas que van invadiendo la pantalla, sino también por los mensajes secretos que apuntan a la figura demoníaca como un operador textual de los sistemas religiosos. Sin embargo, en lugar de situarla como una suerte de horizonte ontológico o de reflexionar sobre su naturaleza como límite y, por lo tanto, anudadora de tiempos según la lógica de la analítica existencial, muy al contrario, parece sugerir una suerte de ultramundo sin posibilidad alguna de redención, y lo que es más interesante, sin paso del tiempo. Absolutamente nada que no sea la propia posición del jugador evoluciona, deviene, se modifica dentro del universo del juego: todo es presa de un estatismo inquietante como si, después de la muerte y la consecuente destrucción de la idea misma de tiempo, lo que quedara fuera ese conjunto de objetos/espacios condenados a permanecer siempre en la misma posición, con las mismas características.

En segundo lugar, nos encontramos con los personajes. En el universo de Sad Satan-especialmente a partir de una de las diferentes versiones filtrades en la red-, aparecieron lo que parecían los moradores de ese extraño laberinto.

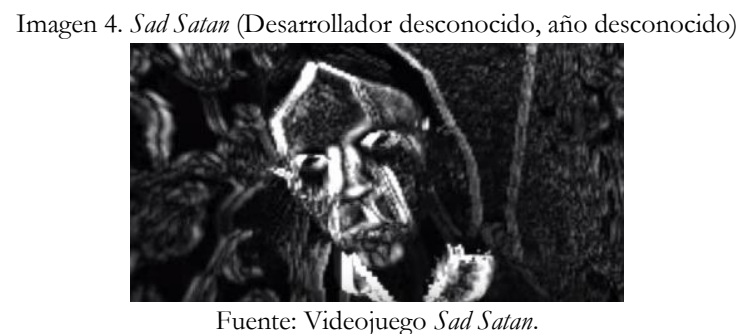

El laberinto está literalmente infectado de figuras aparentemente infantiles cuya conducta resulta difícilmente comprensible en términos de relato. A veces se limitan a mirar las paredes, otras siguen al videojugador con la mirada, a veces escapan y, en el límite, pueden incluso atacar de alguna manera a nuestro personaje, impidiendo que continúe viajando por el laberinto. Sin embargo, su construcción visual también parece estar marcada por esa ausencia de tiempo. Como se puede apreciar en la Imagen 4, el rostro de esos «niños» es al mismo tiempo acusador y está visiblemente envejecido. Al contrario que las imágenes más o menos subliminales que asaltan al jugador, su presencia no es físicamente agresiva: no gritan, no aparecen por sorpresa intentando asustar, sino que simplemente se limitan a comparecer en el mundo, hieráticos, enfermos de ausencia de tiempo. La dinámica misma del «ataque» contra el videojugador resulta también difícilmente explicable en términos de relato: se trata de un simple contacto físico entre la cámara y uno de los personajes -sin gestos de agresividad, sin persecuciones ni ningún tipo de ademán que permita desentrañar su significado.

La única interpretación que parece más o menos plausible tiene que ver, como ya se ha señalado, con los diferentes operadores textuales que contiene el videojuego relacionados o bien con la pedofilia, o bien contra la violencia física contra los menores de edad. Por ejemplo, una de las imágenes que 
asaltan al espectador tiene que ver con las conexiones políticas de Jimmy Savile, el célebre fundador de la «Sociedad de la prevención de la crueldad infantil» que resultó ser un abusador de menores. Lo mismo se puede señalar de algunas imágenes explícitas que diferentes usuarios colocaron a propósito en diferentes versiones «customizadas» del videojuego a través de plataformas como 4 chan ${ }^{5}$. No obstante, y en relación con la nada, la referencia a este tipo de conductas contra los más débiles se puede leer tanto como una suerte de destilación total del pecado original -el mal en estado puro, el punto más bajo en el que se puede situar la experiencia de lo humano-, como desde la perspectiva misma de la herida contra aquellos que, en esencia, todavía no han llegado siquiera a ser hombres o mujeres, esto es, que apenas han podido reunir herramientas para enfrentarse contra ese mal que les ha sido inoculado en la violación. A nosotros, sin duda, lo que nos interesa es la posición en la que nos coloca el propio mecanismo del juego: la de testigos, la de aquellos que miran-poco más podemos hacer, después de todo, en este universo lúdico-, y, por lo tanto, la de aquellos que se ven confrontados explícitamente contra este tipo de actos, esta naturaleza. El hecho mismo de que Sad Satan sea un juego que exija un cierto tipo de acciones poco habituales para instalarlo -ya sea buscar en foros no oficiales, bucear en la Deep Web, visitar canales de distribución notablemente alejados de los mecanismos de distribución habitual de videojuegos- ya dice mucho sobre cómo funciona la mirada, la curiosidad, casi el «rito iniciático» en relación con el mal que el videojugador va, de alguna manera, buscando.

Por último, haremos referencia a los items. Este apartado es, sin duda, el más radical de toda la propuesta. En Sad Satan, de entrada, resulta imposible interactuar con ningún objeto del juego. En términos estrictos, el videojugador en el interior del laberinto no es sino mirada en movimiento y nada más. No puede tocar, usar, guardar, coger o aplicar ningún objeto. No tiene puntos de experiencia que le permitan acceder a ciertos saberes. El bloqueo ontológico es tan brutal que, simple y llanamente, no hay una Existencia que se pueda desplegar. La ausencia de objetos es, a la vez, la ausencia de la posibilidad misma de habitar. Al no incorporar ningún ítem con el que se pueda generar ningún tipo de interacción, el propio juego bloquea nuestro aprendizaje (y el de nuestro personaje) sobre el mundo que le rodea. Nada puede ser descifrado, y, por lo tanto, durante toda la experiencia lúdica somos conscientes de nuestra intencionalidad, esto es, de la manera en la que intentamos percibir, sin éxito, lo que las cosas son y significan.

\section{CONCLUSIONES}

Sin ánimo de agotar la cuestión, creemos estar en disposición de sintetizar, con la mayor brevedad, las principales ideas desarrolladas en el texto:

1. Como hemos podido comprobar, el sistema de juego de Sad Satan está directamente imbricado con una cierta idea de la nada que atraviesa toda la historia cultural de occidente y que la entiende, en su conexión con la maldad, como una experiencia estrictamente negativa -esto es: la nada no es el vacío, sino más bien, la experiencia de una carencia, de una pobreza, de algo «que falta» en el ser.

2. Por lo tanto, los videojuegos pueden ser pensados en relación con la maldad desde una naturaleza estrictamente mimética -es decir, desde la pura mostración del mal y sus efectos-, o,

\footnotetext{
${ }^{5}$ Lógicamente, al tratarse de un juego «abierto» y constantemente modificado por todo tipo de usuarios, las diferentes versiones del mismo se han ido sucediendo durante los últimos meses. Así, por ejemplo, en las primeras versiones no aparecían estos personajes infantiles ni los materiales explícitos. Posteriormente emergió también la llamada clean version, que no contenía dichas imágenes, y que, de alguna manera, se ha convertido en la versión «canónica» del juego, suponiendo que se pueda utilizar esa expresión.
}

(C) Ediciones Universidad de Salamanca / CC BY - NC ND Fonseca, Journal of Communication, n. 14, 2017, pp. 203-214 
por el contrario, desde una naturaleza ontológica -es decir, desde lo que falta para construir un sentido. Ahí se justifica plenamente el análisis de Sad Satan.

3. Los resultados de dicho análisis a partir de la metodología metafísica propuesta por Siabra Fraile nos muestra que Sad Satan bloquea de manera explícita los tres niveles en los que el sentido se construye dentro del videojuego -objetos, ítems, personajes- para que la experiencia del videojugador se conecte, única y exclusivamente, con una experiencia de la ausencia de sentido, esto es, de la nada.

\section{BIBLIOGRAFÍA}

Aristóteles. (2011). Física. Madrid: Gredos.

Aumont, J. (2016). Limites de la ficción. Consideraciones actuales sobre el estado del cine. Santander: Shangrila.

Barlett, C. P., Harris, R. J., \& Baldassaro, R. (2007). Longer you play, the more hostile you feel: Examination of first person shooter video games and aggression during video game play. Aggressive Behavior, 33(6), 486-497. http://doi.org/10.1002/ab.20227

Bogost, I. (2008). The Phenomenology of Videogames. In S. Günzel, M. Liebe, \& D. Mersch (Eds.), Conference Proceedings of the Philosophy of Computer Games 2008 (pp. 22-43). Postdam: Postdam University Press.

Carnagey, N. L., \& Anderson, C. a. (2004). Violent video game exposure and aggression: A literature review. Minerva Psichiatrica, 45(1), 1-18.

Davies, O. (2007). The Haunted: A social story for ghosts. Hampshire: Palgrave Macmillian.

De Hipona, S. A. (2006). La ciudad de Dios. Madrid: Tecnos.

Didi-Huberman, G. (2004). Imágenes pese a todo : memoria visual del Holocausto. Barcelona [etc.]: Paidós.

Dill, K., \& Dill, J. (1999). Video game violence: A review of the empirical literature. Aggression and Violent Behavior, 3, 407-428. http://doi.org/10.1016/s1359-1789(97)00001-3

Fernández Porta, E. (2008). Homo sampler: Tiempo y consumo en la Era Afterpop. Barcelona: Anagrama.

Fernández Porta, E. (2010). €RO\$. La superproducción de los afectos. Barcelona: Anagrama.

Fernández Porta, E. (2012). Emociónese así: anatomía de la alegría (con publicidad encubierta). Barcelona: Anagrama.

Frasca, G. (2003). Ludologists Love Stories, Too: Notes From a Debate That Never Took Place. Game Studies, 92-99. http://doi.org/10.1007/s10055-009-0124-3

Frasca, G. (2009). Juego, videojuego y creación de sentido. Una introducción. Comunicación, 1(7), 37-44.

González Requena, J. (2006). Clásico, manierista, postclásico. Los modos del relato en el cine de Hollywood. Valladolid: Castilla Ediciones.

Heidegger, M. (2001). Introducción a la metafísica. Barcelona: Gedisa.

Heidegger, M. (2009). Ser y tiempo. Madrid: Trotta.

Koster, R. (2005). Theory of Fun for Game Design. Phoenix: Paraglyph Press.

Lanzmann, C. (2011). La liebre de la Patagonia. Barcelona: Seix Barral.

Leibniz, G. W. (2011a). Discurso de metafísica. En Discurso de metafísica, Monadología, Escritos (pp. 79126). Madrid: Gredos.

Leibniz, G. W. (2011b). Escritos filosóficos. Madrid: Gredos.

Loriguillo-López, A., \& Sorolla-Romero, T. (2015). «Vive, muere, repite»: El blockbuster ante el desafío interactivo. Fonseca, Journal of Communication, 11, 118-132.

Navarro Remesal, V. (2016). Libertad dirigida: Una gramática del análisis y diseño de videojuegos. Santander: Shangrila.

Planells, A. J. (2015). Videojuegos y mundos de ficción. Madrid: Cátedra.

Rodríguez Serrano, A. (2006). Entre el videojuego y el cinematógrafo: Películas interactivas. Binaria, 5, $1-7$.

Rodríguez Serrano, A. (2013). Apología de la pornografía en la sociedad del malestar. El Genio Maligno, 12, 37-54. 
Rodríguez Serrano, A. (2014). Holocausto, nazismo y videojuegos: Análisis de Wolfenstein (Raven Software, 2009). Vivat Academia, 127, 83-102.

Rodríguez Serrano, A. (2015). Espejos en Auschwitr. Apuntes sobre cine y holocausto. Santander: Shangrila.

Ruiz Collantes, X. R. (2013). Juegos y videojuegos: Formas de vivencias narrativas. En C. A. Scolari (Ed.), Homo Videoludens 2.0: De Pacman a la gamificación (pp. 20-50). Barcelona: Laboratori de Mitjans Interactius. Universitat de Barcelona.

Siabra Fraile, J. A. (2012). Bosquejo de una metafísica del videojuego. El Ejido: Círculo Rojo.

Wood, R. (2003). Hollywood from Vietnam to Reagan-- and beyond. New York : Columbia University Press.

Zagal, J. P. (2009). Ethically Notable Videogames: Moral Dilemmas and Gameplay. Proceedings of DiGRA 2009, 9.

\section{AGRADECIMIENTO}

Este artículo ha sido posible gracias a la financiación del Ministerio de Economía y Competitividad para el subproyecto $\mathrm{I}+\mathrm{D}$ «El sistema de investigación sobre prácticas sociales en Comunicación: mapa de proyectos, grupos, líneas, objetos de estudio y métodos» (CSO2013-47933-C4-4-P), y de la Universitat Jaume I en el marco del proyecto «La crisis de lo real: la representación documental e informativa en el entorno de la crisis financiera global» (P1·1A2014-05), ambos proyectos bajo la dirección de Javier Marzal Felici.

\section{Fonseca, Journal of Communication}

